Pacific Journal of Mathematics

CONCERNING SEMI-LOCAL-CONNECTEDNESS AND
CUTTING IN NONLOCALLY CONNECTED CONTINUA 


\title{
CONCERNING SEMI-LOCAL-CONNECTEDNESS AND CUTTING IN NONLOCALLY CONNECTED CONTINUA
}

\author{
C. L. Hagopian
}

\begin{abstract}
In this paper relations between semi-local-connectedness and the sets of cut points are established in certain nonlocally connected continua.
\end{abstract}

If a compact metric continuum is not locally connected at any point of a dense $G_{\delta}$ subset and is semi-locally-connected at each point of a dense subset, then the set of weak cut points of the continuum is a first category subset. The presence of a dense $G_{\delta}$ set of weak cut points in a compact metric continuum which is not locally connected at any point of a dense $G_{o}$ subset implies that the continuum is not semi-locally-connected at any point of a dense open subset. If a compact metric continuum is not connected im kleinen at any point of a dense $G_{\delta}$ subset and is semi-locally-connected at each point of a dense subset, then the set of points which separate the continuum is nowhere dense. The presence of a dense set of separating points in a compact metric continuum which is not connected im kleinen at any point of a dense $G_{\delta}$ subset implies that the continuum is not semi-locally-connected at any point of a dense open set. If a semi-locally-connected compact metric continuum is not connected im kleinen at any of its points, then the set of weak cut points in the continuum is nowhere dense and countable.

Throughout this paper, $M$ is a compact connected metric space. A point $p$ of $M$ is said to be a weak cut point of $M$ provided that $M-\{p\}$ contains two distinct points $x$ and $y$ such that every subcontinuum of $M$ containing $\{x, y\}$ contains $p$. Under these conditions $p$ is said to cut $M$ weakly between $x$ and $y$. A point $p$ of $M$ is said to be a separating point of $M$ provided that $M-\{p\}$ is not connected. For the definitions of unfamiliar terms and phrases see [5], [6], and [8].

Theorem 1. If $D$ is an open subset of $M$ and $J$ is a $G_{o}$ subset of $M$ which is dense in $D$ and which has the property that $M$ is not locally connected at any point of $J$, and $M$ is semi-locally-connected at each point of a dense subset of $D$, then the set $C$ of weak cut points of $M$ which are contained in $D$ is a first category subset of $M$. (Note that $C$ may be void.)

Proof. Assume that $C$ is a second category set in $M$. For each 
positive integer $n$, define $C_{n}=\{x \in C \mid$ for some pair of points $\{y, z\}$ in $M-S(x, 1 / n)$, the point $x$ cuts $M$ weakly between $y$ and $z\} . \quad(S(x, 1 / n)$ is the circular region with its center at the point $x$ and its radius $1 / n)$. Since $C=\mathrm{U}_{n} C_{n}$, there exists a positive integer $n$ such that $\bar{C}_{n}$ (the closure of $C_{n}$ ) contains an open set. It follows that there exists an open set $G$ and a subset $R$ of $C_{n} \cap G$ such that $R$ is dense in $G$ and for each point $x$ in $R$ there is a pair of points $\{y, z\}$ in $M-G$ such that $x$ cuts $M$ weakly between $y$ and $z$. For each positive integer $n$, define $G_{n}=\{x \in \bar{G} \mid$ each open subset of $S(x, 1 / n)$ which contains $x$ is not connected\}. Note that $\bar{G}_{n} \subset G_{n+1}$ and therefore $J \cap \bar{G}=\bigcup_{n} G_{n}=$ $\mathrm{U}_{n} \overline{G_{n}}$. The set $J \cap \bar{G}$ is a second category subset of $M$. It follows that for some positive integer $m$, the set $G_{m}$ contains an open set $W$. There exists an open set $U$ in $W$ such that for each point $x$ in $U$ every open subset of $U$ containing $x$ is not connected (i.e., $U$ does not contain an open connected subset). Note that for each open subset $V$ of $U$, none of the components of $V$ are open in $V$.

There exists a point $p$ in $U$ such that $M$ is semi-locally-connected at $p$. It follows that there exists a finite collection of mutually disjoint continua $H_{1}, H_{2}, \cdots, H_{n}$ in $M-\{p\}$ which cover $M-U$. Let $V=$ $U-\bigcup_{i=1}^{n} H_{i}$. The set $V$ is open and contained in $U$. Since no component of $V$ is open in $V$, one can conclude that $V$ has infinitely many components. Because $\bar{R} \supset G \supset V$, the set $R$ must meet infinitely many of the components of $V$.

Consider the continuum $H_{1}$ and the closed set $\cup_{i=2}^{n} H_{i}$. There exists a component $K_{1}$ of $V$ such that $\bar{K}_{1}$ meets both $H_{1}$ and $\cup_{i=2}^{n} H_{i}$. Define $L_{1}$ to be the subcollection of $H_{1}, H_{2}, \cdots, H_{n}$ consisting of continua which meet $\bar{K}_{1}$. Let $H_{1}^{\prime}$ be the continuum $\bar{K}_{1} \cup L_{1}^{*}\left(L_{1}^{*}=\bigcup_{H_{i} \in L_{1}} H_{i}\right)$. There exists a component $K_{2}$ of $V$ such that $\bar{K}_{2}$ meets both $H_{1}^{\prime}$ and the closed set $F_{1}=\left(\cup_{i=1}^{n} H_{i}\right)-L_{1}^{*}$. Define $L_{2}$ to be the subcollection of $H_{1}, H_{2}, \cdots, H_{n}$ consisting of continua which meet $\bar{K}_{2}$. Let $H_{2}^{\prime}$ be the continuum $H_{1}^{\prime} \cup \bar{K}_{2} \cup L_{2}^{*}$ and continue the process. Clearly after a finite number of steps the elements of $H_{1}, H_{2}, \cdots, H_{n}$ will be connected by a finite collection $K$ of closures of components of $V$. For each point $x$ of $V-K^{*}$ and each pair of points $\{y, z\}$ in $M-G$, the continuum $\left(\cup_{i=1}^{n} H_{i}\right) \cup K^{*}$ contains $\{y, z\}$ and misses $x$. It follows that no point of $V-K^{*}$ cuts $M$ weakly between two points in $M-G$. But $R$ must meet $V-K^{*}$. This contradicts the choice of $R$. Therefore $C$ is a first category subset of $M$.

Corollary. If $M$ is not locally connected at any point of a dense $G_{\delta}$ subset of $M$ and is semi-locally-connected at each point of a dense subset of $M$, then the set of weak cut points of $M$ is a first category subset of $M$. 
THEOREM 2. If $M$ is not locally connected at any point of a dense $G_{\delta}$ subset of $M$ and $M$ contains a dense $G_{\delta}$ set of weak cut points, then $M$ is not semi-locally-connected at any point of a dense open set.

Proof. For each open set $U$ in $M$, there exists an open set $V$ contained in $U$ such that $M$ is not semi-locally-connected at any point of $V$ (Theorem 1). It is therefore possible to define a dense open subset of $M$ which has the desired property.

Grace has asked the following question. "Does each compact metric continuum which is totally nonsemi-locally-connected on a dense open set contain a dense $G_{\delta}$ set of weak cut points?" See [3]. If this is the case, then Theorem 2 provides a characterization of those "totally" nonlocally connected, compact metric continua which are not semilocally-connected at each point of a dense open subset.

One might hope to put further restrictions on the set of weak cut points or the set of separating points in nonlocally connected continua of the type mentioned in Theorem 1. Grace has described a compact plane continuum which is not locally connected at any point and is semi-locally-connected at each point of a dense subset. This continuum contains a countable dense set of separating points [2]. Therefore the result stated in Theorem 1 is sharp for nonlocally connected continua. However it is possible to put further limitations on these sets in certain nonconnected im kleinen continua.

Theorem 3. If $D$ is an open subset of $M$ and $J$ is a $G_{o}$ subset of $M$ dense in $D$ which has the property that $M$ is not connected im kleinen at any point of $J$, and $M$ is semi-locally-connected at each point of a dense subset of $D$, then the set of points in $D$ which separate $M$ is nowhere dense in $D$.

Proof. Let $C$ denote the set of points in $D$ which separate $M$. Assume that $C$ is somewhere dense in $D$. It follows that $\bar{C} \cap D$ contains an open set $G$ such that each component of $G$ is nowhere dense [2, Lemma 2]. Since $M$ is compact, the boundary of $G$ is compact. Let $p$ be a point of $G$ such that $M$ is semi-locally-connected at $p$. It follows that there is a finite collection of continua $H$ in $M-\{p\}$ whose interiors cover the boundary of $G$. Let $U=\left(M-H^{*}\right) \cap G$. The set $U$ is open in $M$ and contains $p$. Since the components of $G$ are nowhere dense and $U \subset G \subset \bar{C}$, there exists an infinite sequence $K_{1}, K_{2}, \cdots$ of distinct components of $G$ and an infinite sequence $x_{1}, x_{2} \cdots$ of points such that for each positive integer $j$, the point $x_{j}$ is in $K_{j} \cap C \cap U$. For each $j$, let $M-\left\{x_{j}\right\}=A_{j} \cup B_{j}$, where $A_{j}$ and $B_{j}$ are separated sets. The set $A_{j} \cup\left\{x_{j}\right\}$ is a continuum which contains a point of $G$ in its interior and therefore meets the boundary of $G$. The $x_{j}$-component 
of $G \cap\left(A_{j} \cup\left\{x_{j}\right\}\right)$, which is a subset of $K_{j}$, meets an element $H_{j}$ of $H$. Apply the same argument to $B_{j} \cup\left\{x_{j}\right\}$. Let $H_{j}^{\prime}$ denote an element of $H$ which meets the $x_{j}$-component of $G \cap\left(B_{j} \cup\left\{x_{j}\right\}\right)$. Since $A_{j}$ and $B_{j}$ are separated, $H_{j}$ and $H_{j}^{\prime}$ are distinct elements of $H$ each of which meet $K_{j}$. Note that $K_{j}$ is the only component in $K_{1}, K_{2}, \ldots$ which meets both $H_{j}$ and $H_{j}$, for if this were not the case, then $x_{j}$ would not separate $M$ between $H_{j}$ and $H_{j}^{\prime}$. But for each $j$, the component $K_{j}$ must meet two distinct elements of $H$. This contradicts the fact that $H$ is a finite collection. Therefore $C$ is nowhere dense.

COROLlaRY. If $M$ is not connected im kleinen at any point of $a$ dense $G_{\delta}$ subset of $M$ and is semi-locally-connected at each point of a dense subset of $M$, then the set of points which separate $M$ is nowhere dense in $M$.

From Theorem 1 one can conclude that the set of weak cut points in the continuum $M$ in the preceding corollary is a first category subset. The following example indicates that this result is sharp.

EXAMPLE 1. A compact continuum $M$ in Euclidean 3-space which is totally nonaposyndetic, hence nowhere connected im kleinen, locally remotely connected on a dense subset, hence semi-locally-connected on a dense subset, and which contains a dense set of weak cut points. ${ }^{1}$

In [2] a compact plane continuum $H$ is described which has the property that each connected open subset of $H$ is dense in $H$. This continuum is the common part of a sequence $H_{1}, H_{2}, \cdots$ of nested continua contained in the unit disk. The continuum $H$ is connected im kleinen at each point of the dense $G_{o}$ subset $R$ of $H$ consisting of the points that for each $i$, are interior points of $H_{i}$. Note that $H$ is also locally remotely connected at each point of $R$. Let $T$ denote the dense set of points which separate $H$. Let $p$ be the point of $H_{1}$ which separates $H_{1}$ into infinitely many components. Let $S$ be the topological product of $H$ and the cantor set $C$. Define the continuum $M$ to be the decomposition of $S$ in which the set of points $V$ in $S$ with first coordinate $p$ is shrunk to a point $v$. See the figure.

Since $H$ is nonaposyndetic at $p, M$ is nonaposyndetic at the point $v$. If $q$ is a point of $M-\{v\}$, clearly $M$ is nonaposyndetic at $q$ with respect to $v$. Hence $M$ is totally nonaposyndetic.

Define $D$ to be the set of all points $(x, y)$ in $M$ such that $x$ is in $R$. Obviously, $D$ is a dense subset of $M$. Furthermore, $M$ is locally remotely connected at each point of $D$. To see this let $(x, y)$ be a

${ }^{1}$ A continuum $M$ is said to be locally remotely connected at a point $p$ if for each open set $U$ in $M$ containing $p$ there exists an open set $V$ such that $p \in V \subset U$ and $M-V$ is connected (F. B. Jones) 


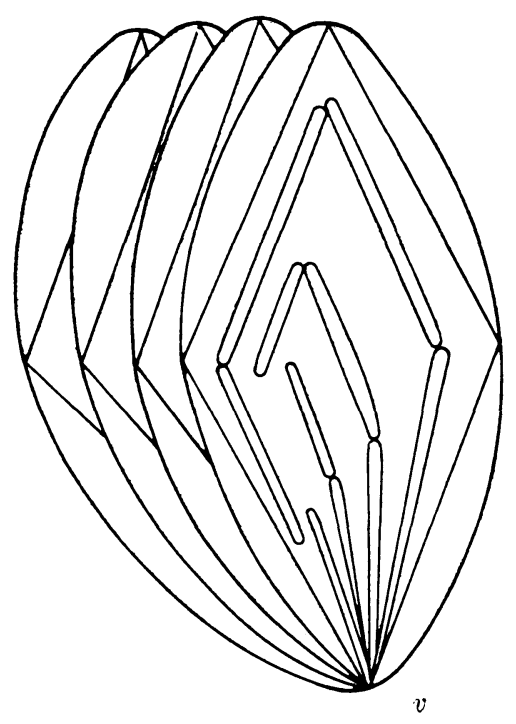

point of $D$ and let $G$ be an open set in $M$ which contains $(x, y)$. Since $H$ is locally remotely connected at $x$, there exists an open set $Q$ in $H-\{p\}$ such that $x \in Q \subset$ (the projection of $G$ into $H)-\{v\}$ and $H-Q$ is connected. There exists a positive real number $d$ such that the neighborhood $N$ of $(x, y)$, which consists of all points $(p, q)$ in $M$ with $p$ in $Q$ and $y-d<q<y+d$, is contained in $G$. Since $v$ is not contained in $N$, it is clear that $M-N$ is connected.

Let $E$ denote the set of points $(x, y)$ in $M$ such that $x$ is in $T$. The set $E$ is dense in $M$. Each point of $E$ weakly cuts $M$. Note that $v$ is the only point which separates $M$.

THEOREM 4. If $M$ is not connected im kleinen at any point of a dense $G_{o}$ subset of $M$ and $M$ contains a dense set of separating points, then $M$ is not semi-locally-connected at any point of a dense open set.

Proof. For each open set $U$ in $M$, there exists an open set $V$ contained in $U$ such that $M$ is not semi-locally-connected at any point of $V$ (Theorem 3). Therefore one can define a dense open subset of $M$ on which $M$ is not semi-locally-connected at any point.

Consider the class of totally nonaposyndetic continua which are semi-locally-connected at each point of a dense open set. The continuum in [4, Example 3] is in this class and, the set of weak cut points in this continuum is a nowhere dense set. The following theorem indicates that this will always be the case for continua of this type.

THEOREM 5. If $M$ is not connected im kleinen at any point of a dense $G_{\delta}$ subset of $M$ and is semi-locally-connected at each point 
of a dense open subset of $M$, then the set of weak cut points is nowhere dense in $M$.

Proof. If $M$ is semi-locally-connected at a point $x$, and $x$ cuts $M$ weakly, then $x$ separates $M$ [7]. The corollary to Theorem 3 indicates that the set of separating points in $M$ is nowhere dense. Since the only other weak cut points in $M$, are in the complement of a dense open subset of $M$, the set consisting of all points which cut $M$ weakly must be nowhere dense.

THEOREM 6. If $M$ is semi-locally connected but not connected im kleinen at any of its points, then the set of weak cut points in $M$ is nowhere dense and countable.

Proof. Let $C$ denote the set of points which cut weakly in $M$. Each point of $C$ separates $M$ [7]. The fact that $C$ is nowhere dense follows immediately from Theorem 3.

$M$ is not regular at any point of $C$ [6, Th. 76, p. 129]. Since all but countably many separating points of $M$ have order 2 , it follows that $C$ must be countable [6, Th. 33, p. 292].

It is easily seen that the proof of Theorem 6 can be modified to allow $M$ to be connected im kleinen on a countable set and not semilocally-connected at any point of a countable set.

By joining together in a suitable fashion infinitely many copies of the continuum in [1, Example 2], it is possible to construct a compact plane continuum which is semi-locally-connected and not connected im kleinen at any of its points but which has a countably infinite set of separating points.

\section{BIBLIOGRAPHY}

1. E. E. Grace, Cut sets in totally nonaposyndetic continua, Proc. Amer. Math. Soc. 9, (1958), 98-104.

2. Totally nonconnected im kleinen continua, Proc. Amer. Math. Soc. 9, (1958), 818-821.

3. Cut points in totally non-semi-locally-connected continua, Pacific J. Math. 14 (1964), 1241-1244.

4. C. L. Hagopian, On generalized forms of aposyndesis (soon to appear in the literature)

5. F. B. Jones, Concerning non-aposyndetic continua, Amer. Math. 70 (1948), 403-413.

6. R. L. Moore, Foundations of point set theory, American Mathematical Society Colloquium Publications, Volume 13, Rhode Island, 1962.

7. G. T. Whyburn, Semi-locally-connected sets, Amer. J. Math. 61 (1939), 733-749.

8. Analytic topology, American Mathematical Society Colloquium Publications, Volume 18, Rhode Island, 1963.

Received October 9, 1968, and in revised form February 10, 1969. 


\section{PACIFIC JOURNAL OF MATHEMATICS}

\section{EDITORS}

H. ROYDEN

Stanford University

Stanford, California

\section{RichaRd PIERCE}

University of Washington Seattle, Washington 98105
J. DugundJI

Department of Mathematics

University of Southern California

Los Angeles, California 90007

BASIL GORDON

University of California

Los Angeles, California 90024

\section{ASSOCIATE EDITORS}
E. F. BECKENBACH
B. H. NeUMANN
F. WOLF
K. YOSHIDA

\section{SUPPORTING INSTITUTIONS}

UNIVERSITY OF BRITISH COLUMBIA CALIFORNIA INSTITUTE OF TECHNOLOGY

UNIVERSITY OF CALIFORNIA

MONTANA STATE UNIVERSITY

UNIVERSITY OF NEVADA

NEW MEXICO STATE UNIVERSITY

OREGON STATE UNIVERSITY

UNIVERSITY OF OREGON

OSAKA UNIVERSITY

UNIVERSITY OF SOUTHERN CALIFORNIA

\author{
STANFORD UNIVERSITY \\ UNIVERSITY OF TOKYO \\ UNIVERSITY OF UTAH \\ WASHINGTON STATE UNIVERSITY \\ UNIVERSITY OF WASHINGTON \\ AMERICAN MATHEMATICAL SOCIETY \\ CHEVRON RESEARCH CORPORATION \\ TRW SYSTEMS \\ NAVAL WEAPONS CENTER
}

The Supporting Institutions listed above contribute to the cost of publication of this Journal, but they are not owners or publishers and have no responsibility for its content or policies.

Mathematical papers intended for publication in the Pacific Journal of Mathematics should be in typed form or offset-reproduced, double spaced with large margins. Underline Greek letters in red, German in green, and script in blue. The first paragraph or two must be capable of being used separately as a synopsis of the entire paper. It should not contain references to the bibliography. Manuscripts, in duplicate if possible, may be sent to any one of the four editors. Please classify according to the scheme of Math. Rev. 36, 1539-1546. All other communications to the editors should be addressed to the managing editor, Richard Arens, University of California, Los Angeles, California, 90024.

50 reprints are provided free for each article; additional copies may be obtained at cost in multiples of 50 .

The Pacific Journal of Mathematics is published monthly. Effective with Volume 16 the price per volume (3 numbers) is $\$ 8.00$; single issues, $\$ 3.00$. Special price for current issues to individual faculty members of supporting institutions and to individual members of the American Mathematical Society: $\$ 4.00$ per volume; single issues $\$ 1.50$. Back numbers are available.

Subscriptions, orders for back numbers, and changes of address should be sent to Pacific Journal of Mathematics, 103 Highland Boulevard, Berkeley, California, 94708.

PUBLISHED BY PACIFIC JOURNAL OF MATHEMATICS, A NON-PROFIT CORPORATION

Printed at Kokusai Bunken Insatsusha (International Academic Printing Co., Ltd.), 7-17. Fujimi 2-chome, Chiyoda-ku, Tokyo, Japan. 


\section{Pacific Journal of Mathematics}

\section{Vol. 30, No. $3 \quad$ November, 1969}

Willard Ellis Baxter, Topological rings with property $(Y) \ldots \ldots \ldots \ldots . \ldots 5$

Sterling K. Berberian, Note on some spectral inequalities of $C . R$.

Putnam ..................................... 573

David Theodore Brown, Galois theory for Banach algebras . ........... 577

Dennis K. Burke and R. A. Stoltenberg, A note on p-spaces and Moore spaces ........................................ 601

Rafael Van Severen Chacon and Stephen Allan McGrath, Estimates of positive contractions....................................... 609

Rene Felix Dennemeyer, Conjugate surfaces for multiple integral problems in the calculus of variations ........................... 621

Edwin O. Elliott, Measures on countable product spaces.............. 639

John Moss Grover, Covering groups of groups of Lie type .............. 645

Charles Lemuel Hagopian, Concerning semi-local-connectedness and cutting in nonlocally connected continua .................. 657

Velmer B. Headley, A monotonicity principle for eigenvalues ........... 663

John Joseph Hutchinson, Intrinsic extensions of rings . . . . . . . . . . . . . 669

Harold H. Johnson, Determination of hyperbolicity by partial

prolongations .................................. 679

Tilla Weinstein, Holomorphic quadratic differentials on surfaces in $E^{3} \ldots 697$

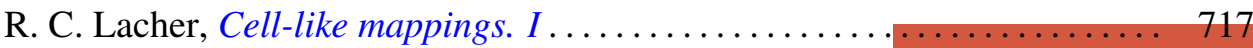

Roger McCann, A classification of centers

Curtis L. Outlaw, Mean value iteration of nonexpansive mappings in a

Banach space...

Allan C. Peterson, Distribution of zeros of solutions of a fourth order

differential equation.

Bhalchandra B. Phadke, Polyhedron inequality and strict convexity .. 765 Jack Wyndall Rogers Jr., On universal tree-like continua .

Edgar Andrews Rutter, Two characterizations of quasi-Frobenius rings

G. Sankaranarayanan and C. Suyambulingom, Some renewal theorems concerning a sequence of correlated random variables...

Joel E. Schneider, A note on the theory of primes........ . .

Richard Peter Stanley, Zero square rings .................

Edward D. Tymchatyn, The 2-cell as a partially ordered space

Craig A. Wood, On general Z.P.I.-rings................ 